\title{
Predictors for the development of preoperative oxygenation impairment in acute aortic dissection in hypertensive patients
}

\author{
Xuemin Zhao ${ }^{1}$ and Mengjun Bie ${ }^{2^{*}}$ (D)
}

\begin{abstract}
Background: Acute aortic dissection (AAD) is an acute life-threatening cardiovascular disease, which is frequently complicated with oxygenation impairment $(\mathrm{OI})$. We aim to investigate predictors of the development of $\mathrm{Ol}$ in the patients with AAD.

Methods: We retrospectively collected clinical data of AAD in hypertensive patients from July 2012 to March 2020. The patients included in this study were divided into Ol (+) group (oxygenation index $\leq 200)$ and OI (-) group (oxygenation index> 200). Both groups were compared according to demographic and clinical characteristics, and laboratory findings. Characteristics of hypertension in the patients with AAD were described. Predictors for the development of $\mathrm{OI}$ were assessed. And cutoff values were determined by receiver operating characteristics (ROC) curve.

Results: A total of 208 patients were included in this study and the incidence of Ol was $32.2 \%$. In OI (+) group, patients had significantly higher peak body temperature ( $37.85 \pm 0.60$ vs $37.64 \pm 0.44{ }^{\circ} \mathrm{C}, P=.005$ ), higher levels of CRP ( $42.70 \pm 28.27$ vs $13.90 \pm 18.70 \mathrm{mg} / \mathrm{L}, P=.000)$ and procalcitonin $(1.07 \pm 3.92 \mathrm{vs} 0.31 \pm 0.77 \mu \mathrm{g} / \mathrm{L}, P=.027)$, and lower levels of albumin ( $34.21 \pm 5.65$ vs $37.73 \pm 4.70 \mathrm{~g} / \mathrm{L}, P=.000$ ). Spearman's rank correlation test showed that the minimum oxygenation index was positively correlated with albumin, and was negatively correlated with the peak body temperature, serum CRP, procalcitonin, BNP and troponin. The stepwise multiple linear regression analysis showed that the peak body temperature, serum CRP and albumin were independently associated with development of Ol. An optimal cutoff value for CRP for predicting OI was $\geq 9.20 \mathrm{mg} / \mathrm{L}$, with a sensitivity of $91.0 \%$ and a specificity of $61.0 \%$.

Conclusions: The peak body temperature, serum CRP and albumin were independent predictors of OI development in the patients with AAD. The serum CRP on admission $\geq 9.20 \mathrm{mg} / \mathrm{L}$ might be a valuable and reliable indicator in predicting the development of OI.
\end{abstract}

Keywords: Acute aortic dissection, Oxygenation impairment, Systemic inflammatory response syndrome, C-reactive protein, Albumin

\footnotetext{
* Correspondence: 513193406@qq.com

2Department of Cardiothoracic Surgery, The First Affiliated Hospital of

Chongqing Medical University, Chongqing 400016, China

Full list of author information is available at the end of the article
}

(C) The Author(s). 2020 Open Access This article is licensed under a Creative Commons Attribution 4.0 International License, which permits use, sharing, adaptation, distribution and reproduction in any medium or format, as long as you give appropriate credit to the original author(s) and the source, provide a link to the Creative Commons licence, and indicate if changes were made. The images or other third party material in this article are included in the article's Creative Commons licence, unless indicated otherwise in a credit line to the material. If material is not included in the article's Creative Commons licence and your intended use is not permitted by statutory regulation or exceeds the permitted use, you will need to obtain permission directly from the copyright holder. To view a copy of this licence, visit http://creativecommons.org/licenses/by/4.0/ The Creative Commons Public Domain Dedication waiver (http://creativecommons.org/publicdomain/zero/1.0/) applies to the data made available in this article, unless otherwise stated in a credit line to the data. 


\section{Background}

Acute aortic dissection (AAD) is a life-threatening cardiovascular disease with high mortality [1-3]. AAD can cause several organs damage, such as acute lung injury, heart hypofunction, and dysfunction of liver and kidney, etc. Oxygenation impairment (OI) is frequently complicated in the patients with AAD due to acute lung injury, with a reported incidence of up to more than a half [4, 5]. Patients with OI may necessitate mechanical ventilation, and long-term use of ventilator probably can lead to pulmonary infections which can prolong the use of mechanical ventilation and increase intensive-care unit stay. Hence, it is very important to predict OI prior to the occurrence of it in the patients with AAD.

OI remains a great challenge for surgeons, physicians and anesthetists during perioperative periods. Doctors known very little about the pathogenesis, prevention and managing strategy in terms of this severe respiratory complication and some doctors are even not aware of it. Currently the occurrence of OI can't be predicted at the very early stage of hospitalization, so that the patients with potential occurrence of OI can't receive appropriate therapeutic management in advance. We consider that interventional therapy before the occurrence of OI was feasible and effective way to achieve better prognosis.

The development of OI is considered to be associated with systemic inflammatory reactions after aortic injury $[6,7]$. So the inflammatory makers have been investigated in predicting $\mathrm{OI}$ in the patients with AAD in several studies. A recent study indicated that OI in Stanford type-B AAD was correlated with a higher peak level of C-Reactive protein (CRP) and a younger age [6]. Manabu Kurabayashi and his colleagues found that the peak level of CRP and the percentage of the volume of false lumen to aorta were negatively correlated with the occurrence of OI in distal type AAD [8]. Kazunori Tomita et al. reported that body mass index $\geq 22 \mathrm{Kg} / \mathrm{m}^{2}$, body temperature on admission $>36.5^{\circ} \mathrm{C}$, and oxygenation index on admission $<300$ were reliable predictors for OI development [7].

The studies related to the prediction of OI development were all retrospective and observational with relatively small sample size, and conclusions were different. Additionally, chronic inflammation usually exists in the course of hypertension and can be drivers of some cardiovascular diseases [9]. A previous study indicated that early use of beta-blockers could prevent excessive inflammation and OI in distal type AAD [10]. However, it is unknown whether there is a correlation between development of $\mathrm{OI}$ and hypertensive characteristics, including hypertension course, hypertension grade, previous blood pressure control, and antihypertensive strategy. For these reasons, it is very necessary to further investigate the predictors of $\mathrm{OI}$ development in the patients with AAD. In this present study, we aim to increase the doctors' awareness of OI development, describe the hypertensive characteristics and investigate the predictors of $\mathrm{OI}$ development $\mathrm{t}$ in the patients with AAD.

\section{Methods \\ Selection of patients}

Our study was conducted in a comprehensive teaching hospital using a retrospective, observational design. The study was approved by the medical ethics committee of our hospital. All data were retrospectively collected from medical records, so written informed consent was not required. And there is no conflict of interest to declare in this study. Between July 2012 and March 2020, a total of 262 consecutive patients were diagnosed with AAD in hypertensive patients. The patients with other etiologies were not included in this present study, such as bicuspid aortic valve disease, Marfan syndrome and trauma, etc. We excluded the patients with elapsed time from the onset of symptoms to admission more than $24 \mathrm{~h}(n=$ 16), inadequate clinical records $(n=1)$, and patients receiving emergent operations $(n=26)$. We also exclude the patients with concomitant diseases which can impair oxygenation function, including pulmonary infections $(n=3)$, moderate to large pleural effusion $(n=2)$, cardiac dysfunction $(n=2)$, myocardial infarction $(n=1)$, moderate to large hydropericardium $(n=2)$, and acute cerebral infarction $(n=1)$. After applying these exclusive criteria, a total of 208 patients were ultimately included in this present study.

\section{Study protocol}

Data regarding demographic and clinical characteristics, and laboratory findings of the patients were retrospectively collected from their medical records. Hypertensive characteristics were especially collected, including hypertension duration, hypertension grade, antihypertensive therapy, previous blood pressure control and development of hypertensive cardiopathy. Blood samples were obtained on admission and results of laboratory examinations were collected, including blood routing test, CRP, procalcitonin, D-dimer, liver and kidney function, markers of myocardial damage, B-type natriuretic peptide (BNP), and glucose. The arterial oxygen tension $\left(\mathrm{PaO}_{2}\right)$ was measured using an automatic blood gas analyzer system (5700, Instrumentation Laboratory, MA, USA). The baseline value of $\mathrm{PaO}_{2}$ was measured at the admission, and we reassessed the value within the first $24 \mathrm{~h}$ after admission and at least every $24 \mathrm{~h}$ thereafter. The oxygenation index was calculated by $\mathrm{PaO}_{2}$ dividing by fraction of inspired oxygen, and OI was defined as minimum oxygenation index $\leq 200$. The patients in this study were divided into OI (+) group (oxygenation 
index $\leq 200)$ and OI $(-)$ group (oxygenation index $>200$ ). Clinical variables were compared between the two groups, and hypertensive characteristics were described. Correlation between clinical variables and the occurrence of OI were investigated and predictors for OI development were assessed.

All the patients were diagnosed based on the results of contrast medium-enhanced computed tomography. Echocardiography was also performed in the early stage of hospitalization. The type of AAD was classified according to the DeBakey classification.

\section{Statistical analysis}

All statistical analysis was performed using the SPSS 21.0 software for windows (SPSS, Chicago, IL, USA). Mean \pm standard deviation, median values, and minimummaximum values were used for continuous data, while percentages were used for categorical variables. The Student $\mathrm{t}$-test was used for continuous variables between the two groups, and categorical variables were compared using the chi-square test. Spearman's rank correlation test was used to assess the correlation between the minimum oxygenation index and clinical variables. A stepwise multiple linear regression analysis was performed to determine the independent predictors of OI development. The receiver operating characteristics (ROC) curve analysis was performed to determine the cutoff value of significant clinical variables in prediction of OI. Statistically significant variables (i.e., $P<$.05) found by Spearman's rank correlation test were included in the stepwise multiple linear regression analysis. Two-tailed $P$ value $<.05$ was considered to be statistically significant.

\section{Results}

The baseline demographic and clinical characteristics of the patients are summarized in Table 1 . The mean age was $56.6 \pm 12.6$ years, ranging from 26 to 87 years; 171 (82.2\%) patients were male. The development of OI was observed in $67(32.2 \%)$ patients on hospital day $2.4 \pm 1.5$ on average (Fig. 1). The elapsed time from onset of symptoms to admission to hospital was $9.90 \pm 6.92 \mathrm{~h}$, ranging from $1.0-24.0 \mathrm{~h}$, showing no significant difference between the two groups. Mechanical ventilation was used in $22(32.8 \%)$ patients in OI $(+)$ group, including $18(26.9 \%)$ patients with invasive mechanical ventilator and $4(6.0 \%)$ patients with non-invasive mechanical ventilator. All the patients were diagnosed with hypertension, and hypertensive characteristics were shown in Table 2. 153 (73.56\%) patients had a history of hypertension with $8.0 \pm 6.7$ years (ranging from 3 months -40 years), and the other $55(26.44 \%)$ patients were diagnosed with hypertension after admission to hospital.

Compared with OI (-) group, patients in OI (+) group had significantly higher peak body temperature, higher levels of CRP and procalcitonin, and lower levels of albumin (Table 1). The body temperature peaked on $3.1 \pm$ 1.4 days in OI $(+)$ group and $2.9 \pm 1.3$ days in OI $(-)$ group on average. No significant differences were indicated by statistical analysis in the terms of other inflammation related markers, including platelet count, white blood cell count and neutrophil percentages. Distribution of the patients' DeBakey classification and hypertensive characteristics showed similar between the two groups.

Table 3 showed that the minimum oxygenation index was significant and positively correlated with albumin, and was negatively correlated with the peak body temperature, serum CRP, procalcitonin, troponin and BNP in Spearman's rank correlation test. Correlation between hypertensive characteristics and development of OI was not indicated by statistical analysis. The other variables with weak associations were subsequently excluded for stepwise multiple linear regression analysis. Serum CRP, albumin and peak body temperatures were found to be independent predictors of the occurrence of OI in stepwise multiple linear regression analysis (Table 4). In ROC curve analysis, an optimal cutoff value for CRP in predicting OI was $\geq 9.20 \mathrm{mg} / \mathrm{L}$, with a sensitivity of $91.0 \%$ and a specificity of $61.0 \%$. The sensitivity and specificity of CRP were indicated to be reliable in the prediction of OI development due to significant larger area under curve (AUC) than peak body temperature and albumin (Fig. 2). The AUC for CRP was 0.840 (95\% CI: $0.780-0.901)$. The AUC for albumin was 0.306 (95\% CI: 0.225-0.387), and the AUC for peak body temperature was 0.600 (95\% CI: 0.514-0.687).

\section{Discussion}

In our study, OI occurred in 67 patients (32.2\%) on hospital day $2.4 \pm 1.5$ on average, and 22 patients (32.8\%) in OI group necessitated mechanical ventilation. The high incidence of OI development in AAD patients and risks of use of mechanical ventilation highlight the importance to predict this severe respiratory complication. However, limited is known about the pathogenesis, prevention and management. This study indicated that the occurrence of OI can be predictable in the patients with AAD. Elevated serum CRP levels and peak body temperature, and decreased albumin levels were independent predictor of OI development.

Inflammatory cells and cytokines have been found in participating in the pathogenesis of aortic dissection [11, 12]. The first stage of inflammatory reactions is the long-term chronic inflammation in the aorta in the patients with hypertension. Inflammation, oxidative stress and genetic predisposition play great roles in the pathogenesis of hypertension [13]. Chronic low-grade inflammation exists in the course of hypertension, triggers the 
Table 1 Baseline demographic characteristics, clinical features, and laboratory results of the patients ${ }^{a}$

\begin{tabular}{|c|c|c|c|}
\hline Variables & $\begin{array}{l}\text { Ol (+) group } \\
(n=67)\end{array}$ & $\begin{array}{l}\text { Ol (-) group } \\
(n=141)\end{array}$ & $P$ \\
\hline Age (years) & $56.8 \pm 12.6$ & $56.6 \pm 12.6$ & 0.896 \\
\hline Gender (male/female) & $51 / 16$ & $120 / 21$ & 0.124 \\
\hline Body mass index & $25.37 \pm 4.68$ & $25.29 \pm 2.99$ & 0.869 \\
\hline Elapsed time after onset (hours) & $10.7 \pm 6.7$ & $9.5 \pm 7.0$ & 0.263 \\
\hline Current smoker & $56.72 \%(38)$ & $59.57 \%(84)$ & 0.764 \\
\hline Alcohol drinking & $44.78 \%(30)$ & $41.13 \%(58)$ & 0.654 \\
\hline Body temperature (admission) $\left({ }^{\circ} \mathrm{C}\right)$ & $36.59 \pm 0.27$ & $36.55 \pm 0.28$ & 0.436 \\
\hline The peak body temperature $\left({ }^{\circ} \mathrm{C}\right)$ & $37.85 \pm 0.60$ & $37.64 \pm 0.44$ & 0.005 \\
\hline Heart rate (beats per minute) & $84.4 \pm 16.5$ & $82.1 \pm 15.7$ & 0.331 \\
\hline Respiratory rate (breaths per minute) & $20.1 \pm 2.4$ & $19.9 \pm 3.0$ & 0.584 \\
\hline Systolic blood pressure $(\mathrm{mmHg})$ & $155.8 \pm 34.1$ & $156.2 \pm 28.6$ & 0.925 \\
\hline Diastolic blood pressure (mmHg) & $90.2 \pm 19.5$ & $90.2 \pm 19.4$ & 0.999 \\
\hline Platelet count $\left(\times 10^{9} / \mathrm{L}\right)$ & $165.8 \pm 60.5$ & $164.7 \pm 68.4$ & 0.900 \\
\hline White blood cell count $\left(\times 10^{9} / \mathrm{L}\right)$ & $12.31 \pm 3.38$ & $12.50 \pm 3.91$ & 0.745 \\
\hline Neutrophil percentage (\%) & $86.19 \pm 7.18$ & $85.36 \pm 7.25$ & 0.245 \\
\hline C-Reactive protein (mg/L) & $42.70 \pm 28.27$ & $13.90 \pm 18.70$ & 0.000 \\
\hline Procalcitonin (ug/L) & $1.07 \pm 3.92$ & $0.31 \pm 0.77$ & 0.027 \\
\hline D-dimer (mg/L) & $9.51 \pm 12.28$ & $9.30 \pm 13.43$ & 0.912 \\
\hline Albumin (g/L) & $34.21 \pm 5.65$ & $37.73 \pm 4.70$ & 0.000 \\
\hline Serum creatinine (umol/L) & $102.13 \pm 78.44$ & $91.13 \pm 44.67$ & 0.200 \\
\hline Creatine kinase-muscle/brain (ug/L) & $2.88 \pm 5.37$ & $3.55 \pm 10.09$ & 0.608 \\
\hline Troponin (ug/L) & $0.029 \pm 0.058$ & $0.033 \pm 0.079$ & 0.654 \\
\hline B-type natriuretic peptide (ng/L) & $124.76 \pm 73.00$ & $150.81 \pm 183.48$ & 0.264 \\
\hline Serum glucose (mmol/L) & $6.90 \pm 2.27$ & $6.98 \pm 2.36$ & 0.812 \\
\hline DeBakey classification & & & 0.749 \\
\hline Type I & $29.85 \%(20)$ & $31.91 \%(45)$ & \\
\hline Type II & 0 & $1.42 \%(2)$ & \\
\hline Type IIla & $4.48 \%(3)$ & $4.26 \%(6)$ & \\
\hline Type IIIb & $65.67 \%(44)$ & $62.41 \%(88)$ & \\
\hline
\end{tabular}

${ }^{a} P<.05$ was considered as significant

progress of hypertension and contributes to vascular remodeling [9, 14, 15]. Angiotensin II also serves an important inflammatory roles in hypertension; it can induce macrophages to differentiate into the $M-1$ type, secrete proinflammatory cytokines, and stimulate the attachment and migration of leukocytes $[15,16]$. The second stage of inflammatory reactions is the rapid development to acute inflammation after aortic injuries $[5,6]$. And it can subsequently develop to systemic inflammatory reactions syndrome (SIRS) due to uncontrolled inflammatory cascade [17]. Aortic samples from the patients with aortic dissection revealed a large amount of macrophages infiltration [18]. A large number of cytokines have also been found infiltrating the aortic wall of patients with aortic dissection, such as IL-6 and
IL-17 [12]. It was reported that levels of IL-11 and interferon $\gamma$ were increased in blood samples in acute thoracic aortic dissection [19]. In this present study, there was no correlation between the development of $\mathrm{OI}$ and hypertension grade, hypertension course, previous blood control, and antihypertensive strategy, suggesting that the impact of chronic inflammation in hypertension is limited in the development of OI. It was majorly due to the second stage of inflammatory reactions and the severity of SIRS.

Systemic inflammatory reactions play key roles in the pathogenesis of acute lung injuries and the development of OI. Recent studies found that AAD complicated with acute lung injury was highly associated with the macrophages infiltrating the pulmonary interstitial tissue and 


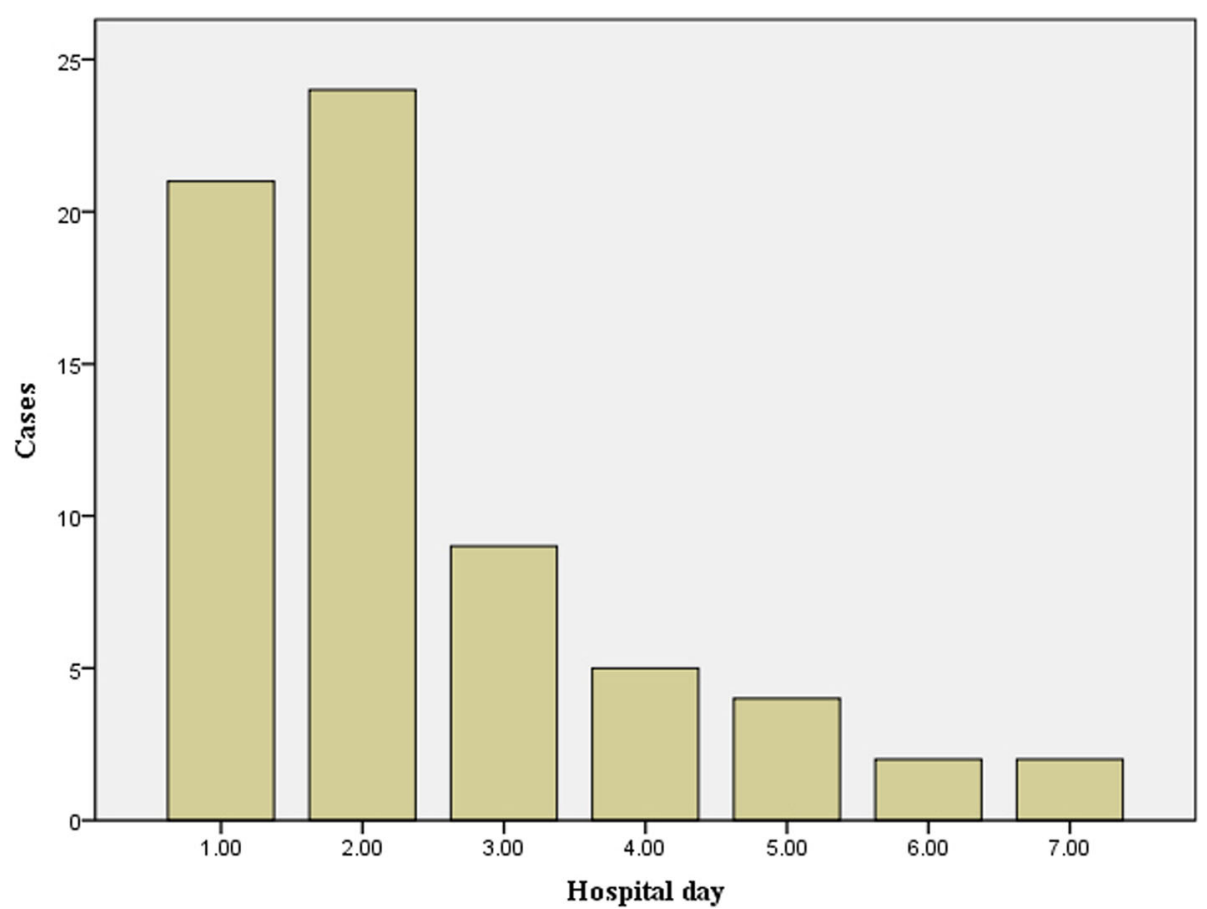

Fig. 1 The timing of occurrence of oxygenation impairment after hospitalization

Table 2 Characteristics of hypertension in the patients with acute aortic disease ${ }^{\text {a }}$

\begin{tabular}{lll}
\hline Variables & Ol (+) group $(n=67)$ & Ol (-) group $(n=141)$ \\
\hline Hypertension duration & $5.87 \pm 6.89$ & $5.99 \pm 6.75$ \\
Hypertension grade & & \\
Grade 1 & $8.96 \%(6)$ & $9.22 \%(13)$ \\
Grade 2 & $20.90 \%(14)$ & $29.08 \%(41)$ \\
Grade 3 & $70.15 \%(47)$ & $61.70 \%(87)$ \\
Antihypertensive agent & & \\
No antihypertensive therapy & $73.13 \%(49)$ & $75.89 \%(107)$ \\
Angiotensin-converting enzyme inhibitors & $11.11 \%(2 / 18)$ & $11.76 \%(4 / 34)$ \\
Angiotensin receptor blockers & $33.33 \%(6 / 18)$ & $26.47 \%(9 / 34)$ \\
Beta-blockers & 0 & $5.88 \%(2 / 34)$ \\
Calcium channel blockers & $61.11 \%(11 / 18)$ & $58.82 \%(20 / 34)$ \\
Chinese traditional medicine & $11.11 \%(2 / 18)$ & $11.76 \%(4 / 34)$ \\
Combination therapy/ Monotherapy & $3 / 18$ & $5 / 34$ \\
Previous blood pressure control & & \\
$<120$ mmHg & 0 & $0.71 \%(1)$ \\
$120-140$ mmHg & $5.97 \%(4)$ & $9.22 \%(13)$ \\
$>140$ mmHg & $94.03 \%(63)$ & $90.07 \%(127)$ \\
Hypertensive cardiopathy & $52.24 \%(35)$ & $60.28 \%(85)$ \\
\hline
\end{tabular}


Table 3 Correlation between clinical variables and minimum oxygenation index indicated by the Spearman rank correlation test ${ }^{a}$

\begin{tabular}{|c|c|c|}
\hline Variables & $r$ & $P$ \\
\hline Age & -0.001 & 0.987 \\
\hline Male & -0.094 & 0.176 \\
\hline Body mass index & -0.067 & 0.339 \\
\hline Elapsed time after onset & -0.039 & 0.580 \\
\hline Current smoker & -0.011 & 0.871 \\
\hline Alcohol drinking & -0.090 & 0.194 \\
\hline Hypertension duration & -0.011 & 0.870 \\
\hline \multicolumn{3}{|l|}{ Hypertension grade } \\
\hline Grade 1 & 0.039 & 0.573 \\
\hline Grade 2 & 0.015 & 0.830 \\
\hline Grade 3 & -0.022 & 0.755 \\
\hline \multicolumn{3}{|l|}{ Antihypertensive agent } \\
\hline No antihypertensive agent & 0.019 & 0.787 \\
\hline $\begin{array}{l}\text { Angiotensin-converting enzyme } \\
\text { inhibitors/Angiotensin receptor blockers }\end{array}$ & -0.027 & 0.700 \\
\hline Beta-blockers & -0.027 & 0.702 \\
\hline Calcium channel blockers & -0.013 & 0.854 \\
\hline Chinese traditional medicine & -0.032 & 0.651 \\
\hline Combination therapy of antihypertensive agents & -0.064 & 0.356 \\
\hline \multicolumn{3}{|l|}{ Previous blood pressure control } \\
\hline$<120 \mathrm{mmHg}$ & -0.092 & 0.185 \\
\hline $120-140 \mathrm{mmHg}$ & 0.069 & 0.321 \\
\hline$>140 \mathrm{mmHg}$ & 0.101 & 0.145 \\
\hline Hypertensive cardiopathy & -0.019 & 0.781 \\
\hline Body temperature on admission & 0.005 & 0.942 \\
\hline The peak body temperature & -0.190 & 0.006 \\
\hline The timing of the peak body temperature & -0.101 & 0.148 \\
\hline Heart rate & -0.053 & 0.448 \\
\hline Respiratory rate & -0.040 & 0.568 \\
\hline Systolic blood pressure & 0.064 & 0.362 \\
\hline Diastolic blood pressure & 0.022 & 0.747 \\
\hline Platelet count & 0.019 & 0.788 \\
\hline White blood cell count & -0.023 & 0.742 \\
\hline Neutrophil percentage & -0.033 & 0.637 \\
\hline C-Reactive protein & -0.420 & 0.000 \\
\hline Procalcitonin & -0.149 & 0.032 \\
\hline D-dimer & -0.101 & 0.147 \\
\hline Albumin & 0.271 & 0.000 \\
\hline Serum creatinine & -0.094 & 0.176 \\
\hline Creatine kinase-muscle/brain & -0.086 & 0.218 \\
\hline Troponin & -0.170 & 0.014 \\
\hline B-type natriuretic peptide & -0.167 & 0.016 \\
\hline Serum glucose & 0.054 & 0.434 \\
\hline DeBakey classification & 0.051 & 0.466 \\
\hline
\end{tabular}

Table 4 A stepwise multiple linear regression analysis of the clinical variables associated with the minimum oxygenation index $^{a}$

\begin{tabular}{lllll}
\hline $\begin{array}{l}\text { Minimum oxygenation } \\
\text { index }\end{array}$ & Coefficient & Standard error & $t$ & $P$ \\
\hline C-Reactive protein & -1.582 & 0.272 & -5.816 & 0.000 \\
Albumin & 4.797 & 1.340 & 3.579 & 0.000 \\
Peak body temperature & -42.629 & 13.873 & -3.073 & 0.002 \\
\hline
\end{tabular}

a $P<.05$ was considered as significant

released matrix metalloproteinases 9 in response to angiotensin II [20, 21]. Inflammatory reactions can cause fluid to leak across alveolar-capillary barrier because of increased permeability and produce enough alveolar edema to cause the clinical characteristics of refractory hypoxemia [22]. In mice model, IL-22 could significantly attenuate the incidence and severity of angiotensin II induced acute lung injury [23]. Hence, concerns on antiinflammatory agents and some protective cytokines will help find insights on the therapeutic strategy for acute lung injury and OI development in AAD. Very limited has been known about the pathogenesis of acute lung injury and OI development in the patients with AAD, so further studies need to be conducted.

Given the great roles of inflammatory reactions in the development of OI, inflammatory markers should be especially investigated in predicting $\mathrm{OI}$ development in the patients with AAD. Inflammatory markers can reflect the severity of SIRS, and in turn it may be predictors of OI development. CRP, a highly sensitive marker of systemic inflammation, is an acute-phase protein induced by proinflammatory cytokines, particularly IL-6 [24]. Elevated CRP was indicated in the patients with AAD [25], and it can be a prognostic factor to be independently associated with inhospital death $[24,26]$. Procalcitonin has also been advocated as a diagnostic parameter in systemic inflammation and infectious diseases [27]. Recent studied showed that postoperative levels of procalcitonin could be used to predict adverse outcome in acute type-A aortic dissection $[28,29]$. We first described the characteristics of procalcitonin in the patients with OI in AAD. Our study showed the negative correlation between the 2 inflammatory markers, CRP and procalcitonin, and the development of OI. The peak body temperature was significantly elevated in the patients with OI and negatively correlated with the occurrence of OI, further increasing the evidence that systemic inflammatory reactions contribute to the development of OI in the patients with AAD. Upon an inflammatory challenge, hepatic and pulmonary macrophages (and later brain endothelial cells) start to release lipid mediators, including prostaglandin $\mathrm{E}_{2}$ and cytokines [30]. Blood prostaglandin $\mathrm{E}_{2}$ enters the brain and triggers fever, and at later stages of fever, prostaglandin $E_{2}$ synthesized within the blood-brain barrier maintains fever [30]. 


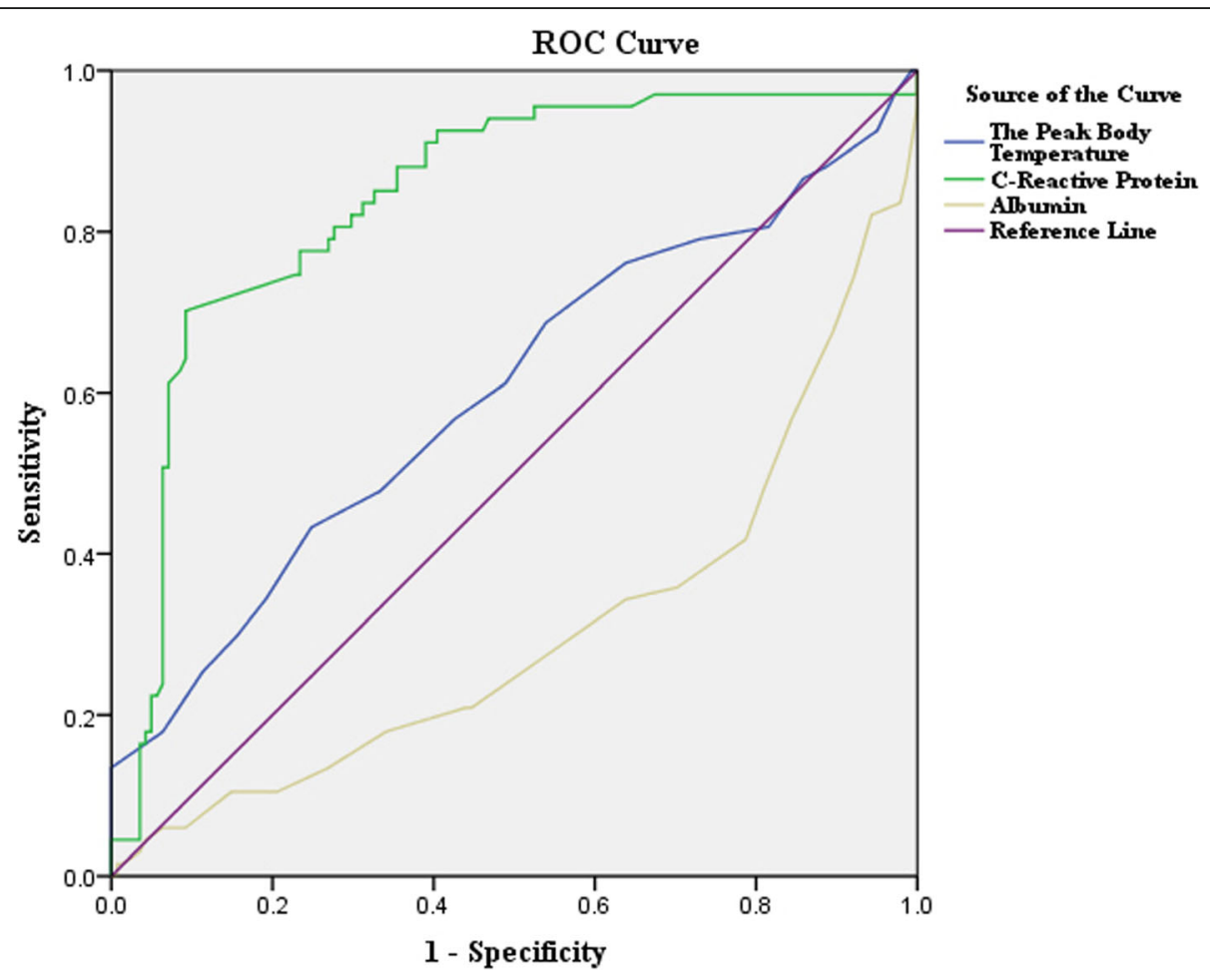

Fig. 2 Receiver operating characteristic (ROC) curves of C-reactive protein (CRP), albumin and peak body temperature for the development of oxygenation impairment in the patients with acute aortic dissection. The area under curve (AUC) for CRP was 0.840 (95\% confidence interval [CI]: 0.780-0.901). The AUC for albumin was 0.306 (95\% Cl: 0.225-0.387). The AUC for peak body temperature was 0.600 (95\% Cl: 0.514-0.687)

Albumin is both an important nutritional indicator and an acute-phase protein involved in inflammatory response [31]. Lower serum albumin levels were indicated in SIRS [32]. Decreased albumin levels have also been found in some cardiovascular diseases, of which inflammatory reaction participates in the pathogenesis, including heart failure and coronary heart disease [33, 34]. Its synthesis is stimulated by hormones and can be inhibited by pro-inflammatory substances, including IL-6 [35]. In inflammatory states, albumin distribution alters from intravascular to extravascular compartments due to increased microvascular permeability [36, 37]. And increased depletion of albumin further leads to the negative albumin balance [37]. We firstly introduce the value of albumin in predicting OI in the patients with AAD. We guess that decreased levels of albumin in the patients with OI are perhaps due to more severe inflammatory reactions.

Stepwise multiple linear regression analysis showed that elevated serum CRP levels, higher peak body temperature and decreased albumin levels were independent predictors of the occurrence of OI. However, the average timing of peak body temperature was later than that of the occurrence of OI, and only CRP had a good sensitivity and specificity indicated by ROC curves. Hence, the predicting value of the peak body temperature and albumin was actually limited. Our study showed that the serum CRP $\geq 9.20 \mathrm{mg} / \mathrm{L}$ might be a valuable predictor of $\mathrm{OI}$ development in AAD patients. CRP is a simple, widely available, and in-expensive test. So it can be widely used as a biomarker in predicting OI in the patients with AAD.

This study also found that most of AAD patients had poor blood pressure control at home. Most of them were grade 3 hypertension and nearly a half had hypertensive cardiopathy. Patients had poor awareness of blood pressure monitoring and regular antihypertensive therapy. Therefore, it highlights the importance of the education of hypertension in public, especially blood pressure monitoring and regular antihypertensive therapy in patients with hypertension.

This study has some limitations. Our study is a singlecenter retrospective study, and the sample size is still not large enough. We will further investigate the expression differences of some cytokines including IL-6 in future. We hope to establish a multicenter, large-sample prospective cohort study focusing on the prevention and management of OI in AAD patients.

\section{Conclusions}

The serum CRP on admission $\geq 9.20 \mathrm{mg} / \mathrm{L}$ may be a valuable inflammatory marker in predicting the development 
of OI in the patients of AAD. And higher peak body temperature and decreased albumin levels may also be helpful indicators of the occurrence of OI. These findings will help identify the patients who are susceptible to have high risks of developing OI, thereby leading to prevention and appropriate interventional therapies prior to the occurrence of OI to gain better prognosis.

\section{Abbreviations}

AAD: Acute aortic dissection; Ol: Oxygenation impairment; CRP: C-Reactive protein; BNP: B-type natriuretic peptide; $\mathrm{PaO} 2$ : Arterial oxygen tension; ROC: Receiver operating characteristics; AUC: Area under curve; SIRS: Systemic inflammatory response syndrome

\section{Acknowledgements}

The authors thank all patients who consented to the enrollment in this study. We also thank Professor Hu Yanming for assistance with improvement in English. No one else than the authors have participated in the design, data collection and analysis, data interpretation, and preparation of this article.

\section{Authors' contributions}

BM conceived the idea. ZX and BM contributed equally to the data collection, data analysis and data interpretation. ZX and BM drafted the manuscript, and then BM reviewed the manuscript. All authors read and approved the final draft.

\section{Funding}

This study was not supported by funding.

\section{Availability of data and materials}

The datasets used and/or analyzed in this present study are available from the corresponding author on reasonable request.

\section{Ethics approval and consent to participate}

This study was carried out following the international ethical recommendations for medical research in humans. Both authors were sure that this study was conducted in accordance with the standards set out in the Declaration of Helsinki. Before starting the study, the Ethical Committee of the first affiliated hospital of Chongqing Medical University approved the study protocol.

\section{Consent for publication}

Not applicable.

\section{Competing interests}

There is no conflict of interest to declare in this study.

\section{Author details}

'Department of Cardiology, The First Branch Hospital, The First Affiliated Hospital of Chongqing Medical University, Chongqing 400016, China.

${ }^{2}$ Department of Cardiothoracic Surgery, The First Affiliated Hospital of Chongqing Medical University, Chongqing 400016, China.

Received: 16 April 2020 Accepted: 4 August 2020

Published online: 10 August 2020

\section{References}

1. De Leon Ayala IA, Chen YF. Acute aortic dissection: an update. Kaohsiung J Med Sci. 2012;28(6):299-305.

2. Gawinecka J, Schonrath F, von Eckardstein A. Acute aortic dissection: pathogenesis, risk factors and diagnosis. Swiss Med Wkly. 2017;147:w14489.

3. Nienaber CA, Clough RE, Sakalihasan N, Suzuki T, Gibbs R, Mussa F, et al. Aortic dissection. Nat Rev Dis Primers. 2016;2:16053.

4. Hasegawa Y, Ishikawa S, Ohtaki A, Otani Y, Takahashi T, Sato Y, et al. Impaired lung oxgenation in acute aortic dissection. J Cardiovasc Surg. 1999;40(2):191-5.

5. Sugano Y, Anzai T, Yoshikawa T, Satoh T, Iwanaga S, Hayashi T, et al. Serum C-reactive protein elevation predicts poor clinical outcome in patients with distal type acute aortic dissection: association with the occurrence of oxygenation impairment. Int J Cardiol. 2005;102(1):39-45.

6. Kashiwagi Y, Komukai K, Suzuki K, Oi Y, Tominaga M, Nakata K, et al. Predictors of oxygenation impairment in medical treatment for type B acute aortic dissection. Heart Vessel. 2018;33(12):1463-70

7. Tomita K, Hata N, Kobayashi N, Shinada T, Shirakabe A. Predicting the occurrence of oxygenation impairment in patients with type-B acute aortic dissection. Int J Angiol. 2014;23(1):53-60.

8. Kurabayashi M, Okishige K, Azegami K, Ueshima D, Sugiyama K, Shimura T, et al. Reduction of the $\mathrm{PaO} 2 / \mathrm{FiO} 2$ ratio in acute aortic dissection relationship between the extent of dissection and inflammation. Circ J. 2010;74(10):2066-73.

9. Mouton AJ, Li X, Hall ME, Hall JE. Obesity, hypertension, and cardiac dysfunction: novel roles of Immunometabolism in macrophage activation and inflammation. Circ Res. 2020;126(6):789-806.

10. Jo Y, Anzai T, Sugano Y, Naito K, Ueno K, Kohno T, et al. Early use of betablockers attenuates systemic inflammatory response and lung oxygenation impairment after distal type acute aortic dissection. Heart Vessel. 2008;23(5): 334-40.

11. Lian G, Li X, Zhang L, Zhang Y, Sun L, Zhang X, et al. Macrophage metabolic reprogramming aggravates aortic dissection through the HIF1alpha-ADAM17 pathway. EBioMedicine. 2019;49:291-304

12. Zeng T, Yuan J, Gan J, Liu Y, Shi L, Lu Z, et al. Thrombospondin 1 is increased in the aorta and plasma of patients with acute aortic dissection Can J Cardiol. 2019;35(1):42-50.

13. Silambanan S, Hermes RS, Bhaskar E, Gayathri S. Endothelial microparticle as an early marker of endothelial dysfunction in patients with essential hypertension: a pilot study. Indian J Clin Biochem. 2020;35(2):245-50.

14. Dixon DL, Wohlford GF, Abbate A. Inflammation and hypertension: causal or not? Hypertension. 2020;75(2):297-8.

15. Piqueras L, Sanz MJ. Angiotensin II and leukocyte trafficking: New insights for an old vascular mediator. Role of redox-signaling pathways. Free Radic Biol Med. 2020;S0891-5849(19):32357-3.

16. Wu L, Chen K, Xiao J, Xin J, Zhang L, Li X, et al. Angiotensin II induces RAW264.7 macrophage polarization to the M1-type through the connexin 43/NF-kB pathway. Mol Med Rep. 2020;21(5):2103-12.

17. Bai Z. Initial research of inflammation with its effect on biomechanical strength of involved aorta in type a aortic dissection and ascending thoracic aortic aneurysm. Anatol J Cardiol. 2018;20(2):85-92.

18. Wang $X$, Zhang H, Cao L, He Y, Ma A, Guo W. The role of macrophages in aortic dissection. Front Physiol. 2020;11:54.

19. Xu Y, Ye J, Wang M, Wang Y, Ji Q, Huang $Y$, et al. Increased interleukin-11 levels in thoracic aorta and plasma from patients with acute thoracic aortic dissection. Clin Chim Acta. 2018;481:193-9.

20. Wu Z, Wang Z, Xu P, Zhang M, Cheng L, Gong B. A novel finding: macrophages involved in inflammation participate in acute aortic dissection complicated with acute lung injury. Curr Mol Med. 2017;17(8):568-79.

21. Wu Z, Ruan Y, Chang J, Li B, Ren W. Angiotensin II is related to the acute aortic dissection complicated with lung injury through mediating the release of MMP9 from macrophages. Am J Transl Res. 2016;8(3):1426-36.

22. Piantadosi CA, Schwartz DA. The acute respiratory distress syndrom. Ann Intern Med. 2004;141:460-70.

23. Ren W, Wang Z, Wu Z, Hu Z, Dai F, Chang J, et al. Corrigendum to "JAK2 STAT3 pathway was associated with the protective effects of IL-22 on aortic dissection with acute lung injury". Dis Markers. 2019:2019:1901626.

24. Wen D, Du X, Dong JZ, Zhou XL, Ma CS. Value of D-dimer and C reactive protein in predicting inhospital death in acute aortic dissection. Heart. 2013; 99(16):1192-7.

25. Liu X, Wang G, Zhang T. The analysis of the levels of plasma inflammationrelated cytokines and endotoxins in patients with acute aortic dissection. Clin Hemorheol Microcirc. 2020. https://doi.org/10.3233/CH-190674.

26. Hsieh WC, Henry BM, Hsieh CC, Maruna P, Omara M, Lindner J. Prognostic role of admission C-reactive protein level as a predictor of in-hospital mortality in type-a acute aortic dissection: a meta-analysis. Vasc Endovasc Surg. 2019;53(7):547-57.

27. Kin H, Kawazoe K, Nakajima T, Niinuma H, Kataoka T, Endo S, et al. Perioperative serum procalcitonin concentrations in patients with acute aortic dissection. Eur Surg Res. 2003:35(5):451-4.

28. Liu H, Luo Z, Liu L, Yang X, Zhuang Y, Tu G, et al. Inflammatory biomarkers to predict adverse outcomes in postoperative patients with acute type aortic dissection. Scand Cardiovasc J. 2020;54(1):37-46. 
29. Liu H, Luo Z, Liu L, Yang XM, Zhuang YM, Zhang Y, et al. Early kinetics of Procalcitonin in predicting surgical outcomes in type a aortic dissection patients. Chin Med J. 2017;130(10):1175-81.

30. Garami A, Steiner AA, Romanovsky AA. Fever and hypothermia in systemic inflammation. Handb Clin Neurol. 2018;157:565-97.

31. Caraceni P, Tufoni M, Bonavita ME. Clinical use of albumin. Blood Transfus. 2013;11(Suppl 4):s18-25.

32. $\mathrm{Xu} H, \mathrm{Hu} \mathrm{L}$, Wei $X, \mathrm{Niu} J, \mathrm{Gao} Y, \mathrm{He} J$, et al. The predictive value of preoperative high-sensitive C-reactive protein/albumin ratio in systemic inflammatory response syndrome after percutaneous Nephrolithotomy. J Endourol. 2019;33(1):1-8.

33. Cinar T, Cagdas M, Rencuzogullari I, Karakoyun S, Karabag Y, Yesin M, et al. Prognostic efficacy of C-reactive protein/albumin ratio in ST elevation myocardial infarction. Scand Cardiovasc J. 2019;53(2):83-90.

34. Nakayama H, Koyama S, Kuragaichi T, Shiba M, Fujiwara H, Takatsu Y, et al. Prognostic value of rising serum albumin during hospitalization in patients with acute heart failure. Am J Cardiol. 2016;117(8):1305-9.

35. Gao N, Yang RN, Meng Z, Wang WH. The prognostic value of C-reactive protein/albumin ratio in nasopharyngeal carcinoma: a meta-analysis. Biosci Rep. 2018;38(6):BSR20180686.

36. Artigas A, Wernerman J, Arroyo V, Vincent J-L, Levy M. Role of albumin in diseases associated with severe systemic inflammation: pathophysiologic and clinical evidence in sepsis and in decompensated cirrhosis. J Crit Care. 2016;33:62-70.

37. Doweiko JP, Nompleggi DJ. The role of albumin in human physiology and pathophysiology, part III: albumin and disease states. JPEN J Parenter Enteral Nutr. 1991;15(4):476-83.

\section{Publisher's Note}

Springer Nature remains neutral with regard to jurisdictional claims in published maps and institutional affiliations.

Ready to submit your research? Choose BMC and benefit from:

- fast, convenient online submission

- thorough peer review by experienced researchers in your field

- rapid publication on acceptance

- support for research data, including large and complex data types

- gold Open Access which fosters wider collaboration and increased citations

- maximum visibility for your research: over $100 \mathrm{M}$ website views per year

At $\mathrm{BMC}$, research is always in progress.

Learn more biomedcentral.com/submissions 